\title{
O MUNDO DOS JURISTAS PELOS OLHOS DO HISTORIADOR
}

The jurists world by the historian's eyes

El mundo de los juristas a través de los ojos del historiador

HESPANHA, António Manuel. Como os juristas viam o mundo (1550-1750): Direitos, estados, pessoas, coisas, contratos, ações e crimes. Lisboa: CreateSpace Independent Publishing Platform (Amazon), 2015. ${ }^{1}$

Paulo Fillipy de Souza Conti*

Palavras-chave: Cultura letrada; Direito comum europeu; Juristas; Portugal (1550-1750).

Keywords: Literate culture; Europe common Law; Jurists; Portugal (1550-1750).

Palabras clave: Cultura letrada; Derecho común europeo; Juristas; Portugal (1550-1750).

O contexto e a intencionalidade da produção dos discursos devem ser levados em conta para que não haja interpretações que fujam das possibilidades apresentadas pela documentação. Mesmo uma leitura feita a contrapelo possui limites interpretativos. A sensibilidade do pesquisador costuma ser bom guia para evitar enganos, mas não pode ser o único. Associar um corpo teórico e metodológico à sensibilidade de pesquisa ajuda na execução de uma obra mais coesa.

Iniciamos o texto com essa reflexão por uma dupla razão. António Manuel Hespanha mesmo se propondo a fazer um livro mais focado na exposição das tradições jurídicas portuguesas e não na análise dessas tradições, não se permite escapar da teoria e do método que caracterizam o trabalho do historiador. A segunda razão é o próprio Hespanha quem introduz. Ele diz que os historiadores ainda esperam encontrar as coisas como elas realmente aconteceram, mesmo que duvidem das narrativas que lhes chegam como fontes. E duvidam ainda mais daquelas que "são muito senhoras de si". Problema que se agrava quando as narrativas em questão são as jurídicas.

O autor resgata a ideia de "uma sociedade construída sobre o direito", consoante o medievalista russo Aaron Gurevič, para demonstrar o nível de abrangência desses textos. Bem como fica expresso no título do livro, “direitos, estados, pessoas, coisas, contratos, ações e crimes", eram todos campos cobertos pela Justiça. E, para cada um desses campos, havia

\footnotetext{
*Mestre em História pela Universidade Federal de Pernambuco. Atualmente, doutorando vinculado ao Programa de Pós-Graduação em História da Universidade Federal de Pernambuco (PPGH - UFPE). Contato: Av. da Arquitetura, s/n, CFCH 10Andar, CDU, CEP: 50740-550, Recife-PE, Brasil. E-mail: paulofconti@gmail.com.
} 
subdivisões. A intenção dos juristas letrados era produzir uma legislação que pudesse dar conta de aspectos muito gerais e, ao mesmo tempo, capaz de arbitrar sobre casos extremamente específicos. A literatura jurídica tendia a fazer uma exposição pormenorizada da organização e do funcionamento social. "Ou seja, os juristas descrevem muito detalhadamente o mundo e muito exaustivamente as razões que movem o mundo; o seu mundo, claro, e as suas razões para o movimento do mundo" (posição 79-81). O que, por vezes, pode conduzir o historiador ao engano de pensar na sociedade portuguesa de Antigo Regime como um corpo homogêneo e seguidor das leis. Mas, havia nuances como a tradição, o prestígio dos sujeitos, as regionalidades, as distâncias, entre outros aspectos que interferiam na forma de dispensar a Justiça. E como bem apontou António Manuel Hespanha no trecho acima citado, o texto jurídico recaia na intencionalidade dos homens responsáveis pela sua produção.

O direito das mulheres pode nos servir de modelo para mostrar como a lei buscava circunscrever do quadro mais geral aos mais específicos. O Antigo Regime português apresenta as mulheres como seres frágeis e facilmente coagidos. O feminino era considerado praticamente inexistente diante do masculino. No entanto,

[...] quando a imagem da sua particular natureza o faz irromper no direito, o próprio direito explicita os traços da sua pré-compreensão da mulher, traços que o saber jurídico amplifica e projeta socialmente em instituições, regras, brocardos e exemplos - fraqueza, debilidade intelectual, olvido, indignidade (posição 7471$7473)$.

Essa avaliação tornava as mulheres juridicamente menos responsáveis pelos seus atos. Elas não poderiam, assim como os rústicos e idiotas, responder pelo crime de falso testemunho, pois lhes seria difícil distinguir a verdade do erro. Porém, em determinados casos a "imprudência" e "fragilidade" feminina eram desconsideradas. As mulheres comerciantes são bons exemplos disso. A prática do comércio seria suficiente para garantir faculdades mais amplas para as mulheres, ainda que não comparáveis às masculinas. A legislação, como é possível notar, não apenas inferiorizava as mulheres como também lhes fechava qualquer possibilidade de obter um posto de mando. Preceito que apenas o monarca tinha poder para constranger.

Conforme alerta Hespanha, o conteúdo do texto jurídico sobre as mulheres no Antigo Regime é dos mais suscetíveis a avaliações feitas de acordo com o entendimento que temos hoje do Direito (e, principalmente, do feminino). A estranheza provocada é normal. Reflete as diferenças entre o presente e o universo social do tempo estudado. Atualmente, no mínimo nos pareceria risível - para citar outro detalhe dentro de atribuições mais amplas - incluir 
entre as cláusulas de um contrato de locação de imóvel a previsão de realocar o inquilino caso a propriedade fosse assombrada por almas penadas. Não obstante, para uma sociedade imersa no pensamento religioso, esta era uma prática possível. Resguardar as diferenças entre os períodos, ou melhor, localizar no tempo determinadas práticas jurídicas é um dos pontos fortes de "Como os juristas viam o mundo (1550-1750)".

Outro ponto forte da obra é não ter preocupações quanto à extensão dos capítulos e muito menos do livro como um todo. O que permite descrições longas sobre os campos cobertos pelo saber jurídico. Isso foi possível porque, ao contrário das suas obras anteriores, o pesquisador realizou a publicação de forma independente. É provável que uma editora aconselhasse o autor a retirar algumas partes para tornar o livro mais "enxuto". Sem essas barreiras, o trabalho surge como uma leitura que também pode ser feita em forma de consulta. Por duas razões. Primeiro devido ao fato de apenas a introdução (capítulo 1) e o epílogo (capítulo 9) adiantarem e reforçarem as ideias apresentadas nos demais capítulos. Os outros sete capítulos são independentes entre si. E, quando a argumentação exige questões já trabalhadas, Hespanha as repete. As argumentações e conceitos só não são repetidos quando um tópico é exatamente igual ao outro em termos interpretativos.

A segunda razão diz respeito à corriqueira dificuldade que os historiadores têm com o universo de escrita dos oficiais da justiça, comumente, carregados de termos técnicos. E, quando os historiadores tentam sanar seus déficits de informação auxiliados por livros de direito atual, "é o pior dos remédios, pois os leva a aprisionar o passado nas categorias do direito de hoje" (posição 131-132). Hespanha prefere o "desconforto" da leitura dos textos clássicos, ao usar compreensões jurídicas que atualmente estão superadas, do que cair no anacronismo. Esse tipo de resguardo metodológico, ele diz ser positivo tanto para os historiadores que lerem a obra, como também para os juristas. Afinal, a aproximação que se busca é com o universo dos magistrados de então.

Para evitar enganos, Hespanha aconselha a leitura de alguns interpretes das leis portuguesas. Sugere aos seus leitores o mesmo que sugere aos seus alunos, a leitura de "Institutiones iuris civilis lusitani", de Pascoal José de Melo Freire dos Reis, publicado em finais do século XVIII, e a obra de Manuel de Almeida e Sousa de Lobão, "Notas de uso practico, e criticas, addições, illustrações e remissões”, datada do início do século XIX. Mas o conselho é seguido por uma ressalva. Por ter sido Pascoal de Melo um reformista e Lobão um conservador, as interpretações de um podem ser facilmente balanceadas pelas do outro. O que não exclui o compromisso que deve ter o profissional da História com a leitura de interpretações feitas para reforçar, reconstruir ou até mesmo extinguir conceitos. 
Se com os autores mencionados no parágrafo anterior é possível ter melhores explicações sobre leis pontuais, o que o livro de António Manuel Hespanha oferece é uma visão melhor sobre a tradição jurídica portuguesa. Dito de outra forma, o livro pode ser consultado para tirar dúvidas sobre as formas de pensar e executar o Direito entre 1550 e 1750. As peças jurídicas eram "uma sofisticada construção de juristas letrados, a partir da qual se estabeleciam regras para a vida de todos os dias. Mas também de uma imagem consistente do homem e da sociedade" (posição 34-35).

Como forma de reprodução social a cultura letrada ajudava a aprofundar as categorias sociais. Os letrados, por dominarem o código de escrita e leitura, não poderiam ser vistos, socialmente, como os que não dominavam o mesmo código. Ainda que o objetivo final da legislação fosse conhecido pela maior parte da população, segundo Hespanha, conhecer as especificidades da lei e ter poder para executá-las era o grande diferencial.

Seja como for, qualquer ato de jurisdição implicava algum poder de dar ordens ou de constranger, quanto mais não fosse a autoridade mínima (modica coertio) que faz com que os atos judiciais sejam reconhecidos e obedecidos pelas partes. Daí que, se podia haver ordens que não estavam precedidas de uma averiguação jurídica (merum imperium), não podia, em contrapartida, haver atos judiciais sem que o magistrado não tivesse algum poder de mandar (imperium qui inest iurisdictioni) (posição 11481153).

A manutenção dos textos jurídicos em latim ou com expressões latinas, por exemplo, ainda que a maior parte estivesse em vernáculo, aparece como "projeto de poder". Não apenas por afastar das pessoas o entendimento fino do texto, como dito acima, mas ajudava igualmente a associar as peças jurídicas do mundo sacro (dos saberes religiosos). Servia ainda para a manutenção das hierarquias profissionais no campo do Direito. Os juízes não letrados seguiam mais o direito natural e comum do que os compêndios universitários. E por isso, eram tratados pelos juízes letrados como executores do "direito dos rústicos" ou dos "direitos próprios" (consuetudinário).

Apesar disso, os livros de direito tinham boa circulação. Eram encontrados nas periferias do Reino e do Império, garantindo assim, "o conhecimento da tradição jurídica letrada nos confins mais afastados, mesmo independentemente de aí existirem juristas" (posição 365-366). Nos centros urbanos eram ainda mais comuns. O que não significa dizer que os juristas dispunham de grandes bibliotecas pessoais. Hespanha diz que a lista de livros referência para o trabalho dos juristas e juízes era curta e, ainda menor era o número de títulos de fato utilizados. Na maioria das vezes, o acesso a essas obras só era possível em instituições com boas bibliotecas. A posse pessoal passava pelas dificuldades do valor, transporte e fragilidade das obras. 
Ao passar a tradição jurídica portuguesa em revista António Manuel Hespanha explora os campos civil e eclesiástico; o que era válido e inválido para nobres e não nobres; versa sobre os compromissos dos reis com a execução da Justiça e etc. Inclusive, de como as penalidades foram se tornando mais brandas com o passar do tempo. Discorre ainda sobre as gentes e as coisas. Aqueles que não gozavam de nenhuma personalidade ou status, como os escravos, não eram considerados como pessoas, senão como coisas. E, objetos inanimados poderiam aparecer como titulares de direitos, ou seja, personificados. Por exemplo, "um prédio podia ser titular de direitos de servidão, a prestar ou por outros prédios (servidões reais) ou por pessoas (servidões pessoais, como a 'adscrição', vinculação de certas pessoas a trabalhar certa terra)" (posição 6391-6393). Havia então, sob a avaliação contemporânea, coisas tratadas como gentes e gentes tratadas como coisas. Ainda assim, ambos poderiam ser requalificados, a depender da situação, e enquadrados em outros campos do Direito

Além do que já foi mencionado e de tantos outros temas que ficaram de fora desse comentário, há uma ideia central que perpassa toda a obra. Neste trabalho, António Manuel Hespanha não apenas reforça a sua famosa tese sobre a distribuição dos poderes por diversos polos, como também introduz uma nova tese (ou provocação historiográfica). Trata a visão jurídica exposta como típica da Europa "latina". O autor reconhece a ousadia da sua afirmação e trata de apresentar algumas razões que o conduzem a tal pensamento. Diz não acreditar em um "espírito latino" ou em uma "cultura latina". Tampouco considera que esse fenômeno possa ser atribuído aos diferentes panoramas religiosos entre "Sul" e "Norte" da Europa após a reforma protestante.

Para Hespanha, o cerne da questão estava de fato no uso e comunicação do corpus literário. Mesmo antes da cisão religiosa, os juristas do "Sul" discutiam entre si, enquanto os do "Norte" (leia-se alemães, holandeses e ingleses) não tinham uma literatura jurídica muito expressiva. Sendo assim, havia um corpus literário comum entre os juristas ibéricos, italianos e até mesmo franceses, na primeira época moderna. "A identidade 'do Sul' é antes uma identidade induzida por um círculo de comunicação" (posição 19801). O que facilita para que parte da historiografia as classifique como corporativas e repletas de falhas de rigor na aplicação das leis. Quem sabe até possa o "sabor latino" do direito comum entre essas sociedades revelar as raízes de parte daquilo que somos hoje.

\section{Notas}

\footnotetext{
1 A obra é vendida exclusivamente pela Amazon. No site da empresa é possível ter acesso ao livro em dois formatos: o físico, com 732 páginas e impresso pela CreateSpace; e digital, com 36.362 posições.
} 